\title{
Article \\ Centrifugation Removes a Population of Large Vesicles, or "Macroparticles," Intermediate in Size to RBCs and Microvesicles
}

\author{
Michael C. Larson ${ }^{1, *(\mathbb{C},}$, Neil Hogg ${ }^{2}$ and Cheryl A. Hillery ${ }^{3}$ \\ 1 Banner University Medical Center-Tucson, University of Arizona, Tucson, AZ 85724, USA \\ 2 Department of Biophysics, Medical College of Wisconsin, Milwaukee, WI 53226, USA; nhogg@mcw.edu \\ 3 Department of Pediatrics, UPMC Children's Hospital of Pittsburgh, Pittsburgh, PA 15224, USA; \\ cheryl.hillery@chp.edu \\ * Correspondence: mikelarson@radiology.arizona.edu or mikelarson@arizona.edu; Tel.: +1-(520)-626-7402
}

Citation: Larson, M.C; Hogg, N.; Hillery, C.A Centrifugation Removes a Population of Large Vesicles, or "Macroparticles," Intermediate in Size to RBCs and Microvesicles. Int. J. Mol. Sci. 2021, 22, 1243. https://doi.org/ $10.3390 /$ ijms 22031243

Academic Editor: Stefano Papa

Received: 1 December 2020

Accepted: 29 December 2020

Published: 27 January 2021

Publisher's Note: MDPI stays neutral with regard to jurisdictional claims in published maps and institutional affiliations.

Copyright: (c) 2021 by the authors. Licensee MDPI, Basel, Switzerland. This article is an open access article distributed under the terms and conditions of the Creative Commons Attribution (CC BY) license (https:/ / creativecommons.org/licenses/by/ $4.0 /)$.

\begin{abstract}
Microparticles or microvesicles (MPs/MVs) are sub-cellular vesicles with a growing number of known biological functions. Microvesicles from a variety of parent cells within the vascular system increase in numerous pathological states. Red blood cell-derived MVs (RMVs) are relatively less studied than other types of circulating MVs despite red blood cells (RBCs) being the most abundant intravascular cell. This may be in part due the echoes of past misconceptions that RBCs were merely floating anucleate bags of hemoglobin rather than dynamic and responsive cells. The initial aim of this study was to maximize the concentration of RMVs derived from various blood or blood products by focusing on the optimal isolation conditions without creating more MVs from artificial manipulation. We found that allowing RBCs to sediment overnight resulted in a continuum in size of RBC membrane-containing fragments or vesicles extending beyond the $1 \mu \mathrm{m}$ size limit suggested by many as the maximal size of an MV. Additionally, dilution and centrifugation factors were studied that altered the resultant MV population concentration. The heterogeneous size of RMVs was confirmed in mice models of hemolytic anemia. This methodological finding establishes a new paradigm in that it blurs the line between RBC, fragment, and RMV as well as suggests that the concentration of circulating RMVs may be widely underestimated given that centrifugation removes the majority of such RBC-derived membrane-containing particles.
\end{abstract}

Keywords: blood; cell membrane microparticles; circulating cell-derived microparticles; cytoplasmic vesicles; erythrocytes; flow cytometry; RBCs; centrifugation

\section{Introduction}

Microparticles or microvesicles (MPs/MVs) are small membrane vesicles shed from cells with the number and cargo varying depending on the stimuli to the parent cell [1-3]. Red blood cell (RBC)-derived MVs (RMVs) are formed constitutively [4,5] and in greater numbers following oxidative damage [6], hemolysis, or even ischemic injury [3,7,8]. Red blood cell-derived MVs carry biologically active macromolecules $[9,10]$, such as exposed phosphatidylserine (PS) and phosphatidylethanolamine [11], which are critical in coagulation [12]. These phospholipids are also important in phagocytic clearance of MVs and dead cells [13-15] and immunomodulation [16,17]. Red blood cell-derived MV membrane proteins also contribute to inflammation [18] and coagulation [19,20]. Internally, RMVs also harbor hemoglobin, which scavenges nitric oxide [21]. Red blood cell-derived MVs have been suggested as mediators of complications of transfusion [10,21-24] and hemolytic anemia [25,26]. MPs/MVs are typically defined as particles with a diameter of $0.1-1 \mu \mathrm{m}$ that expose phosphatidylserine, binding annexin V. Defining a standardized method by which platelet-derived MVs (PMVs) are isolated and counted has only been addressed within the past decade [27-29]. However, these definitions and guidelines for PMVs may 
not be broadly applicable. While PMVs are reportedly the most abundant type of MV circulating in healthy humans, this may differ in individuals with hemolytic anemia, where RMVs circulate in comparable concentrations $[20,25]$. Additionally, a growing number of reports show RBCs/RBC-derived "fragments" or MVs are critical in thrombosis $[18,19,30]$. While there are numerous studies addressing and comparing MV isolation procedures focused on endothelial MVs and PMVs [9,31-34], it is not clear which method is ideal for RMVs, as their parent cells (RBCs) sediment more readily than platelets or other cells. By establishing standardized protocols, cross-institution comparisons may be possible for RMVs as well as PMVs, enabling diagnoses and prognoses based on MVs [27,33].

The initial objective of this study was to understand the effects of centrifugation on RMV quantification, as there are limited reports of RMV quantification as a function of centrifugation speed [9]. Surprisingly, we discovered erythrocyte-derived debris varying in size from roughly $3 \mu \mathrm{m}$ to sub-micron in diameter in aged donor blood that was removed with cells at low centrifugation speeds $(100 \mathrm{~g})$. Blood in hemolytic anemia mouse models also showed vesicles with a large variance in size. This provides evidence of a continuum of RBC-derived particle sizes, suggesting that that the arbitrary $1 \mu \mathrm{m}$ maximal diameter cutoff for what is generally considered a "microparticle" may not apply to bilayer-encapsulated (i.e., vesicular) debris resulting from RBC hemolysis. In addition, this challenges the distinction between "RBC fragments" [30] and smaller "RBC vesicles" [7].

\section{Results}

\subsection{Gentle Sedimentation Revealed Vesicles Larger than $1 \mu \mathrm{m}$ in Diameter}

Flow cytometry was used to quantify RMVs in newly-outdated (43-46 day old) RBC units (Figure 1) as reported previously [11,35]. The RBC-poor supernatant was isolated by allowing RBCs to sediment by gravity overnight, as centrifugation has been shown to decrease resulting MV concentrations [9]. Platelet Endothelial Cell Adhesion Molecule1 (PECAM-1) is a well-established surface marker of platelet and endothelial cell origin. PECAM-1 staining of outdated RBC units was not done in these experiments, as we showed previously the paucity of PECAM-1-derived vesicles in leukoreduced RBC units [11,36].

Figure 1A shows representative forward scatter (representing roughly the size for objects substantially larger than the interrogating light wavelength) and side scatter (corresponding to the internal complexity) dot plots different outdated units, displaying the heterogeneous size of debris resulting from hemolysis over the course of storage (representative 4 out of 11 outdated units). At optimal labeling conditions, only $2.5 \% \pm 1.1 \%$ of events smaller in diameter than $6 \mu \mathrm{m}$ were both PS and glycophorin A negative (Figure 1B-E representative of $n=11$ outdated units) and were disregarded for subsequent analysis as either background noise or true debris devoid of a membrane surface including either PS or glycophorin A; these criteria would include both right-side out (glycophorin A+) and inside-out (glycophorin A-/PS+) vesicles. There consistently were populations of large cell-to-MV intermediates that were clearly larger than the $1 \mu \mathrm{m}$ cut-off normally applied to MVs (which we will refer to as "macroparticles").

Fluorescence microscopy qualitatively validated the flow cytometry data. Figure $1 \mathrm{~F}$ is a brightfield image of RBC-poor supernatant isolated by overnight sedimentation; Figure $1 \mathrm{G}$ is the accompanying glycophorin A fluorescence image. Arrows highlight glycophorin A-positive "macroparticles" (i.e., vesicles larger than the $1 \mu \mathrm{m}$ commonly accepted maximum MV diameter). Quantitative fluorescence measurements of the macroparticles were not attempted given the dependence of the fluorescence signal on the microscope focus as well as the clear inhomogeneous staining of intact RBCs. A summary of previously reported RBC vesicle sizes is shown for comparison (Table 1). 

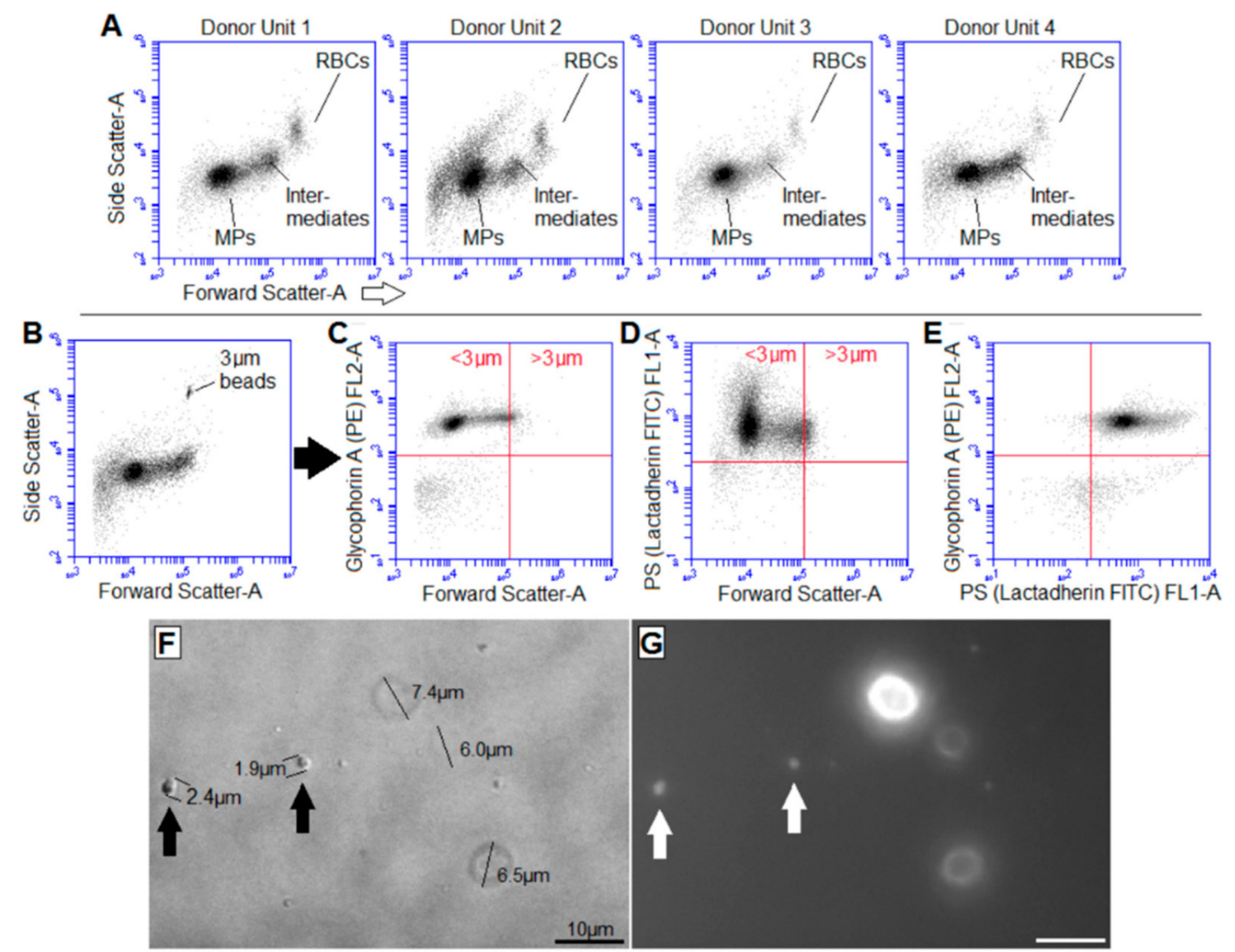

Figure 1. Gentle sedimentation revealed vesicles larger than $1 \mu \mathrm{m}$ in diameter. (A) Representative flow cytometry light scatter (forward scatter-area, or size, and side scatter-area, or internal complexity) dot plots of RBC-poor supernatant isolated by allowing newly-outdated (43-46 day old) donor blood to stand overnight at $4{ }^{\circ} \mathrm{C}$, (B) with $3 \mu \mathrm{m}$ beads added for size comparison. Staining with (C) anti-glycophorin-A antibodies and (D) lactadherin (which binds phosphatidylserine, PS) labeled (E) 97.5\% $\pm 1.1 \%$ of events in 11 expired units' RBC-poor supernatant. (F) Representative bright-field image of cells and vesicles in RBC-poor supernatant and (G) corresponding glycophorin-A fluorescent image showing relative similar fluorescence signal from the "macroparticles" of intact RBCs; arrows highlight vesicles larger than $1 \mu$ m ("macroparticles"). Bar $=10 \mu \mathrm{m}$.

Table 1. Various sizes of red blood cell (RBC) vesicles including the method to isolate them from the parent cell. * Gating excluded events that were larger than $1 \mu \mathrm{m}$ to rule out platelets.

\begin{tabular}{|c|c|c|c|c|}
\hline Source of RBC Vesicles & Cell/Vesicle Separation & $\begin{array}{l}\text { Vesicle } \\
\text { Diameter }\end{array}$ & Examination Method(s) & Reference \\
\hline \multicolumn{5}{|c|}{ (Patho)physiologic RBC Damage or Hemolysis } \\
\hline Malaria & $1500 \times g$ for $15^{\prime}$ & $\leq 1 \mu \mathrm{m} *$ & Flow cytometry & [37] \\
\hline $\begin{array}{l}\text { Hemolytic anemia, } \\
\pm \text { overnight storage }\end{array}$ & $1500 \times g$ for $5^{\prime}$ to remove cells & $\sim 0.25-0.30 \mu \mathrm{m}$ & Light microscopy & {$[8]$} \\
\hline $\begin{array}{l}\text { Autoimmune } \\
\text { thrombocytopenia }\end{array}$ & $200 \times g$ for $8^{\prime}$ to remove cells & Up to $2 \mu \mathrm{m}$ & $\begin{array}{l}\text { Electron } \\
\text { microscopy }\end{array}$ & [5] \\
\hline Various diseases & $1550 \times g$ for $20^{\prime}$ to remove cell & $0.05-1 \mu \mathrm{m}$ & $\begin{array}{l}\text { Electron } \\
\text { microscopy }\end{array}$ & [38] \\
\hline During blood storage & $\begin{array}{l}\geq 870 \times g \text { for } 20^{\prime} \text { to remove } \\
\quad \text { cells, direct dilution }\end{array}$ & $3 \mu \mathrm{m}, 2.78 \mu \mathrm{m}$ & $\begin{array}{l}\text { Light microscopy, flow } \\
\text { cytometry }\end{array}$ & This study \\
\hline \multicolumn{5}{|c|}{ Laboratory Techniques } \\
\hline $\begin{array}{l}\text { Heating RBCs to } 45^{\circ} \mathrm{C} \\
42^{\circ} \mathrm{C} \text { with } \mathrm{pH} \leq 6\end{array}$ & $\begin{array}{l}\text { Filtered through } 3 \mu \mathrm{m} \\
\text { membrane }\end{array}$ & 1 up to $3.5 \mu \mathrm{m}$ & $\begin{array}{l}\text { Electron } \\
\text { microscopy }\end{array}$ & [39] \\
\hline $\begin{array}{c}\text { Heating RBCs to } 45^{\circ} \mathrm{C} \text { with } \\
\text { EDTA and } \mathrm{Ca}^{2+}\end{array}$ & $\begin{array}{l}\text { Sucrose gradient } \\
\text { centrifugation }\end{array}$ & $0.5-1 \mu \mathrm{m}$ & $\begin{array}{l}\text { Light and electron } \\
\text { microscopy }\end{array}$ & [40] \\
\hline Ionophore $\mathrm{A} 23187$ and $\mathrm{Ca}^{2+}$ & $\begin{array}{l}\text { Centrifugation to sediment } \\
\text { cells }\end{array}$ & $60 \mathrm{~nm}, 100-150 \mathrm{~nm}$ & $\begin{array}{l}\text { Electron } \\
\text { microscopy }\end{array}$ & {$[41,42]$} \\
\hline
\end{tabular}




\subsection{Size Determination of Cell-to-Microparticle Intermediate "Macroparticles"}

While microscopic inspection of RBC-poor supernatant confirmed the presence of membrane vesicles larger than $1 \mu \mathrm{m}$ in diameter, flow cytometry was used for quantification and sizing of the large vesicles. Though sub-micrometer vesicles are better characterized with side scatter (SSC) [29], the apparent diameter of the macroparticles was appropriate for using forward scatter to characterize them using the flow cytometer used in this study [36,43]; vesicles with diameters closer to the wavelength of interrogating light more appropriately are "sized" using side scatter [44].

Figure 2A shows a representative dot plot of the forward scatter (FSC) height and width obtained from $2 \mu \mathrm{m}$ beads. Clear multiplet populations were observed with disproportionate FSC width relative to height. The smallest population of beads was assumed to be singlets and used for subsequent size comparison and estimates (Figure 2B).
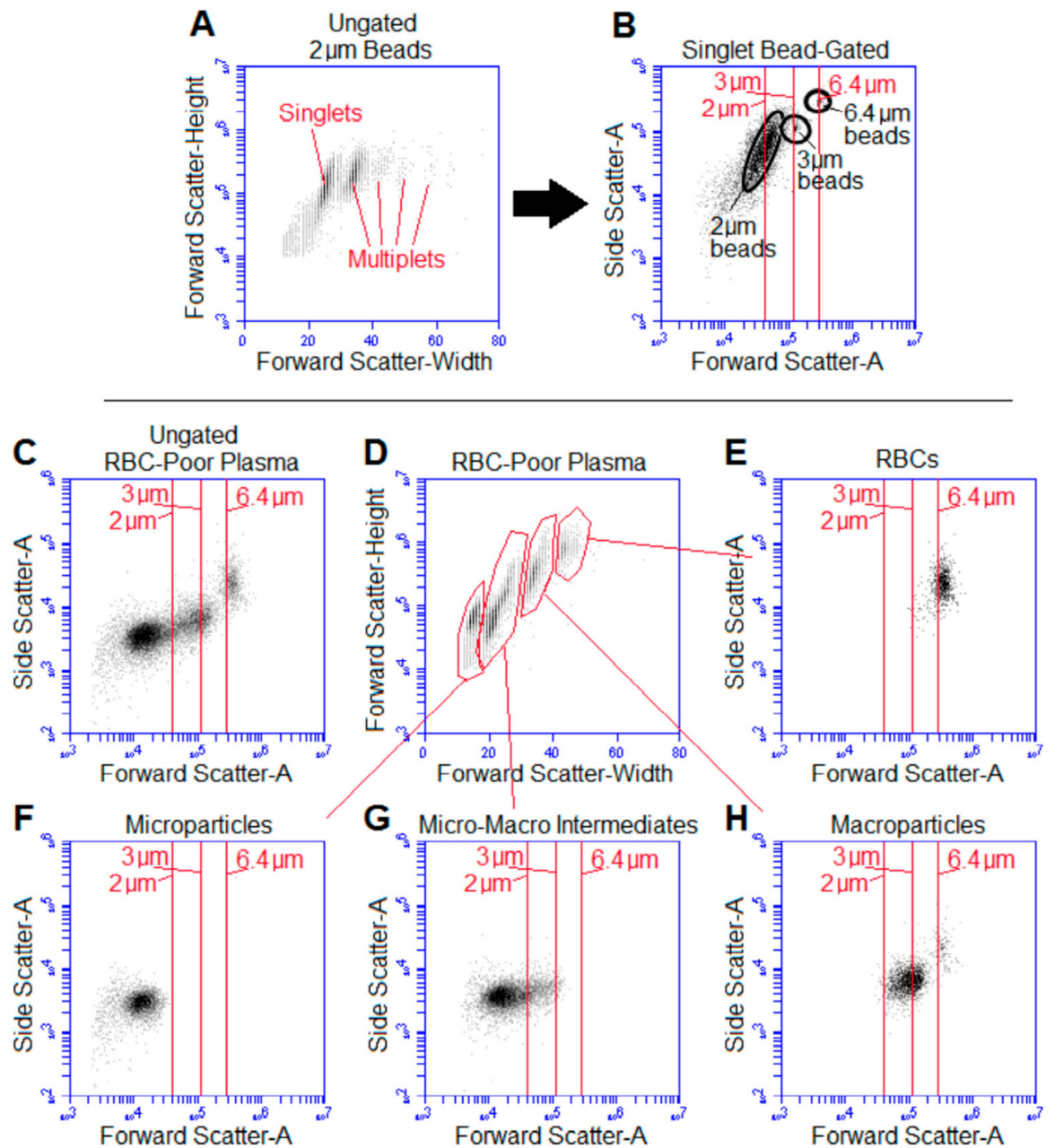

Figure 2. Size determination of cell-to-microparticle intermediate "macroparticles": (A) Example identification of singlets in examining $2 \mu \mathrm{m}$ beads using the forward scatter height by width; multiplets have disproportionately large width relative to height. (B) Light scatter of singlet beads (highlighted in the black circles) of various sizes was used to estimate the size of RBC macroparticles, with vertical lines corresponding to the forward scatter (FSC) of the singlet bead population. (C) Representative ungated RBC-poor supernatant with size windows shown by vertical lines corresponding to bead size based on data from (B). (D) This supernatant was examined for multiplets based on forward scatter height and width and gated to show (E) RBCs, (F) microparticles, (G) intermediately sized vesicles and possible microparticle doublets, and (H) macroparticles. Macroparticles made up 9.4\% $\pm 9.3 \%$ of RBC-poor supernatant events smaller in diameter than $6 \mu \mathrm{m}$ from units 1-4 days after expiration, and their diameter was $2.78 \pm 0.35 \mu \mathrm{m}$ based on their forward scatter height relative to that of the beads; $n=15$ outdated units. 
Figure $2 \mathrm{C}-\mathrm{H}$ shows flow cytometric analysis of a representative RBC-poor plasma supernatant, gated based on its FSC-height by FSC-width (Figure 2D), showing the RBCs (Figure 2E) along with multiple vesicle populations. There was a distinct microparticle population (Figure $2 \mathrm{~F}$ ) and another population in size intermediate to the micro- and macro-particles that may include microparticle multiplets based on the FSC width being disproportionately larger than the FSC-H (Figure 2D). The vesicles we are referring to as macroparticles (Figure $2 \mathrm{H}$ ) made up $9.4 \% \pm 9.3 \%$ of RBC-poor supernatant events smaller in diameter than $6 \mu \mathrm{m}$ from units 1-4 days after expiration, and their diameter was $2.78 \pm 0.35 \mu \mathrm{m}$ based on FSC-H of beads with a known size ( $n=15$ outdated units).

\subsection{Centrifugation Removes Macroparticles}

To investigate the influence of centrifugation on the macroparticle population, centrifugation at various speeds was carried out and compared to no centrifugation (by diluting donor blood for direct measurement with flow cytometry) or overnight sedimentation (centrifugation at " $1 \times g^{\prime \prime}$ ) to produce RBC-poor supernatant. When examining blood directly without centrifugation, an appropriate dilution range was first established (Figure 3A). Figure $3 \mathrm{~B}$ shows representative light scatter dot plots of RBC vesicles less than $6 \mu \mathrm{m}$ in diameter by the various isolation methods. Flow cytometry of diluted donor blood resulted primarily in a signal from whole cells (Figure 3B, panel i), obstructing detection of intermediately sized vesicles/macroparticles clearly seen in Figure 3B, panel ii (overnight $1 \times g$ separation). Centrifugation at $100 \times g$ for 10 min removed the macroparticle population (Figure 3B, panel iii). This was confirmed by a significant decrease in the mean FSC of RBC-excluded events (Figure $3 C$ ). There were significantly more RBC vesicles in the directly-diluted blood compared to the overnight sediment supernatant and significantly fewer at higher centrifugation speeds $(\geq 500 \times g)$ with a speed-dependent exponential decrease in the total RBC vesicles (Figure $3 \mathrm{D}$, inset).

In a parallel study, the effect of dilution before or after centrifugation was investigated. Blood was either centrifuged first and then diluted in M199/Bovine Serum Albumin (BSA) media containing fluorescently labeled antibodies or diluted first and then centrifuged. Figure $4 \mathrm{~A}$ is representative of four donor blood samples (different than the prior 15 outdated units) centrifuged at $50 \times g$ for $5 \mathrm{~min}$ and then diluted 1:1; Figure $4 \mathrm{~B}$ was the same sample diluted first 1:1, and then centrifuged at the same conditions; $3 \mu \mathrm{m}$ beads were added immediately before flow cytometry to confirm cytometer reported RMV concentrations. Both dot plots were of identical volumes examined by flow cytometry. Figure $4 \mathrm{C}$ shows that even after multiplying by the dilution factor, dilution before centrifugation resulted in significantly smaller total of RMVs in the resulting supernatant compared to undiluted and centrifuged blood supernatant. This decrease in MVs was likely due to the decreased viscosity of media compared with the blood supernatant. Solvent viscosity is important in MV centrifugation [45]. Thus, caution is required that MV-containing samples are not diluted into a less viscous media (including anticoagulant) prior to centrifugation to remove cells-otherwise, MVs will also more easily sediment as demonstrated here. 

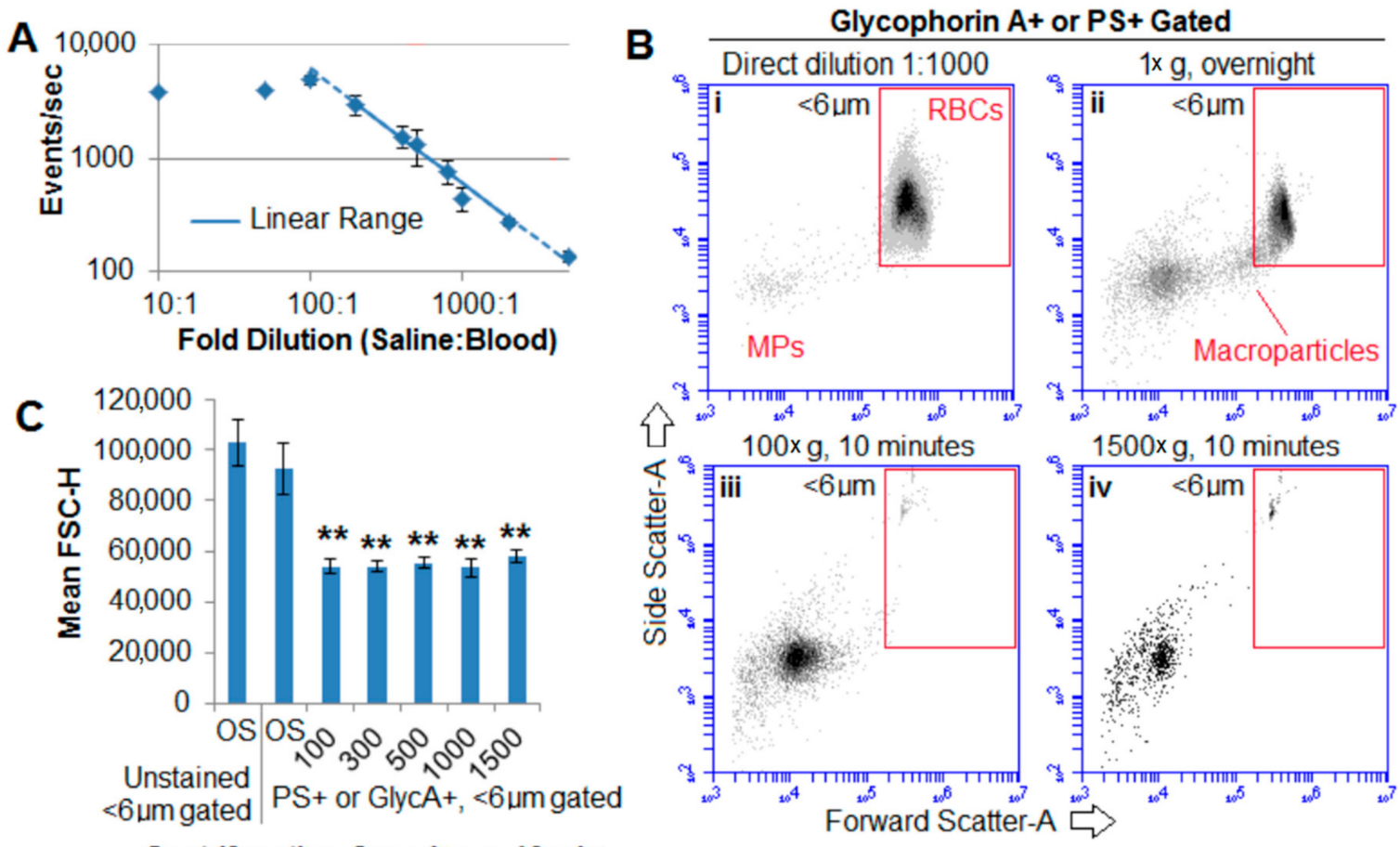

Centrifugation Speed: $x \mathrm{~g}, 10 \mathrm{~min}$

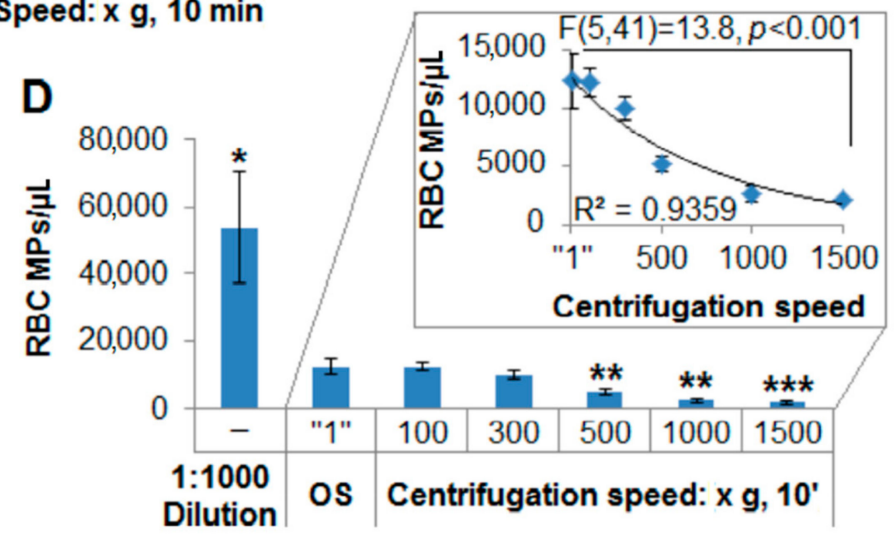

Figure 3. Large vesicles were removed by centrifugation: To examine the effects of centrifugation on the macroparticle population, direct dilution was carried out. (A) The linear range of the cytometer was first established by minimizing the variance of a linear fit of the dilution to event rate; $n=3$ donor units to identify the midpoint of the linear range. (B) Representative light scatter of PS+ or glycophorin A+ events comparing the resulting detected vesicle population. (i) With direct dilution, the RBC population overwhelmed the detection of vesicles (ii) seen with overnight sedimentation. (iii) Even centrifugation at $100 \times g$ for 10 min removed most large vesicles, and (iv) centrifugation at $1500 \times g$ for $10 \mathrm{~min}$ resulted in removal of over $85 \%$ of vesicles compared to overnight sedimentation. (C) There was a significant decrease in the forward scatter height of vesicles $(<6 \mu \mathrm{m})$ at $100 \times g$ or more, showing how the macroparticles are removed with low-speed centrifugation. (D) Compared to supernatant obtained from overnight sedimentation, there were 4.3-fold more vesicles in blood examined with the same settings used for the other supernatants. There was no significant difference in the total concentration of RBC vesicles at low speed $(100$ or $300 \times g)$, but there was a speed-dependent decrease in vesicles relative to supernatant from overnight sedimentation (inset); $n=8-11$ (dilutions only had 8 units, whereas the different sedimentation/centrifugation numbers were performed on all 11). " $1 \times g^{\prime \prime} /$ OS, overnight sedimentation; ${ }^{*} p<0.05$; ** denotes $t$-test $p$-val. $<0.001$, and ${ }^{* * *}<0.0001$ relative to " $1 \times g^{\prime \prime} /$ OS. 

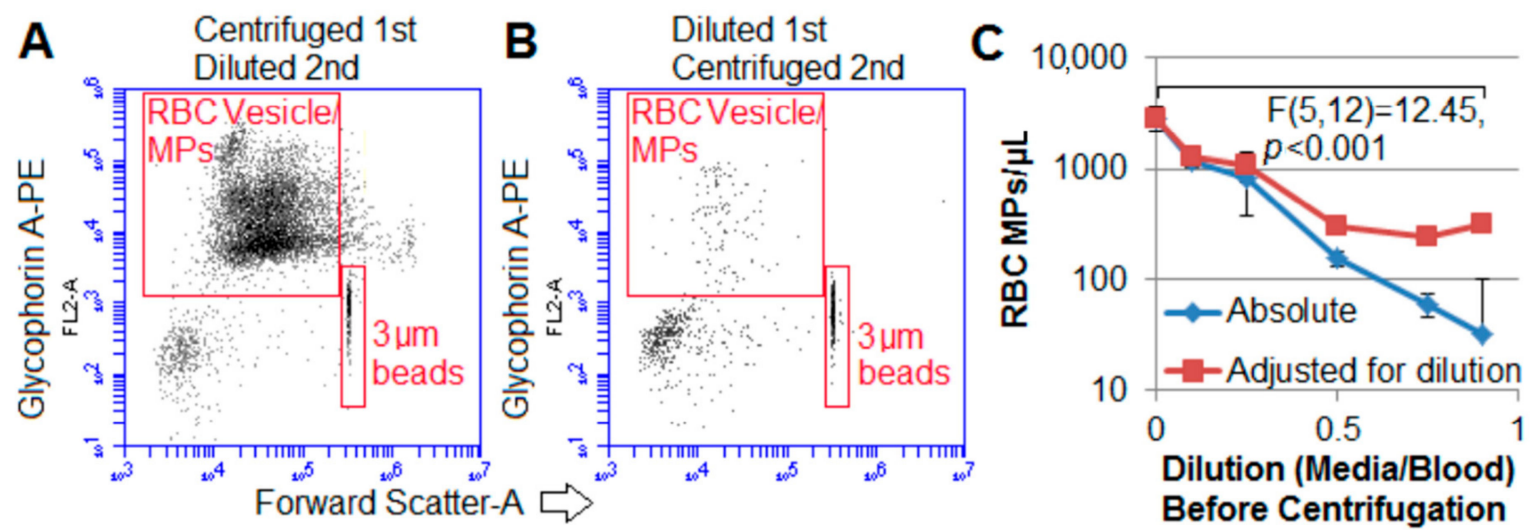

Figure 4. Diluting blood before centrifugation enhances microparticles or microvesicles (MV/MP) sedimentation: The timing of dilution (either before or after centrifugation) was examined. (A) Aliquots of donor blood were centrifuged first, their supernatant removed and diluted 1:1, and then examined. (B) Identical aliquots of blood were first diluted 1:1, then centrifuged, and the supernatant examined. (A,B) Representative glycophorin A and FSC dot plots of two identical aliquots centrifuged for $5 \mathrm{~min}$ at $50 \times g$ then diluted or the reverse. Immediately prior to examination with flow cytometry, $3 \mu \mathrm{m}$ counting beads were added to doubly confirm the cytometer reported volumes, and the dot plots displayed were of identical volumes (representative of 4 donor units). (C) Proof-of-principle showing as the blood became more diluted, centrifugation (for $1500 \times g$ for $15 \mathrm{~min}$ ) resulted in significantly fewer RMVs; $n=3$ ( 1 of the aforementioned 4 samples with the most MVs/MPs performed in triplicate).

\subsection{RBC-Derived MVs Sediment Was Relatively Faster than PECAM-1 + MVs}

Although RBCs are intermediate in size between leukocytes and platelets, RBCs sediment more readily than platelets and leukocytes due the fact of their density. We next examined if RBC-derived MVs would sediment quicker than platelet- and leukocytederived MVs. As proof-of-concept and to minimize any variance in the size of MVs or buffer effects, packed RBCs (diluted in MV-poor autologous plasma obtained by sterile filtration) and platelet-rich plasma from a single healthy donor were separately extruded through $0.45 \mu \mathrm{m}$ filters. This resulted in MV populations with a similar side-scatter height (SSC-H) (Figure 5A) that gave a relative size approximation of small MVs of which the diameter was on the order of interrogating light wavelength $[29,36,46]$.
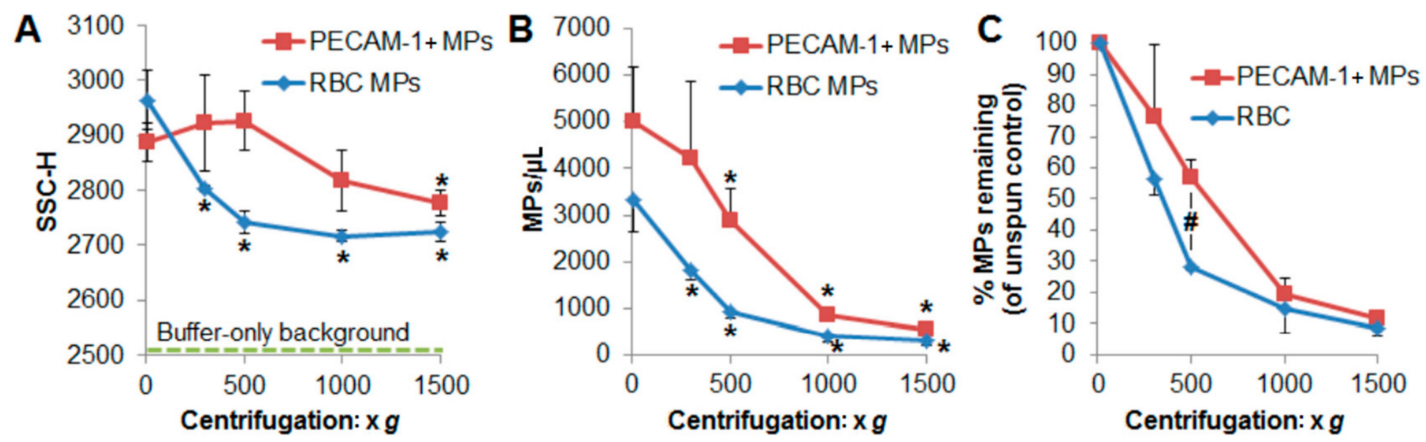

Figure 5. RBC MPs/RMVs sediment at lower speeds than PECAM-1 + MPs. As proof-of-principle, RBCs and platelet-rich plasma were subjected to extrusion through $0.45 \mu \mathrm{m}$ pore size membranes to generate similarly sized MVs and, subsequently, centrifuged at different speeds before flow cytometry enumeration. (A) The relative size of the resulting MV populations (SSC-H) significantly decreased at all centrifugation speeds tested for RMVs, whereas there was no significant difference in the size of PECAM-1 + MVs until subjected to $1500 \times g$. The green dotted line indicates the noise threshold of buffer-only liquid evaluated on the flow cytometer. (B) There was a significant drop in the number of RBC-MVs with any centrifugation speed; however, the decrease in PECAM-1 + MVs was not significant until $500 \times g$ or greater. (C) At $500 \times g$, there were significantly fewer RMVs than PECAM-1 + MVs remaining relative to the initial unspun concentration. * Two-tailed $t$-test, $p<0.05$ compared to unspun; $\# p=0.010$ comparing the percent remaining at $500 \times g$; results are technical triplicates from a single donor. 
Figure 5A shows the relative size of the different MV populations after extrusion and then subjected to centrifugation at various speeds. There was no difference in the SSC-H of the resulting PECAM- 1 MVs with anything less than $1500 \times g$. In contrast, RMVs subjected to speeds as little as $300 \times g$ resulted in significantly smaller MV populations. Figure $5 B$ displays the resulting MV concentrations after centrifugation. There were significantly fewer RBC MVs even at $300 \times g$ centrifugation for $10 \mathrm{~min}$ at $4{ }^{\circ} \mathrm{C}$; however, there was no difference in PECAM-1 + MVs compared to unspun samples at $300 \times g$. When normalized to the initial unspun MV concentrations, there were significantly fewer RMVs remaining at $500 \times g$ compared to PECAM-1 + MVs remaining (Figure 5C). Thus, consistent with the sedimentation pattern of their parent cells; RBC-derived MVs may sediment more readily than other MV types.

\subsection{MVs May Adhere to RBCs}

As shown in Figure 3D, there was a significant discrepancy in the RMV concentration measured in dilute blood compared with supernatant isolated by $1 \times \mathrm{g} /$ overnight sedimentation. To determine the fate of the "missing" RMVs, MVs were labeled with a lipophilic fluorescent dye, DiI, and the MVs washed. To control for any unbound dye, the third wash buffer was used to dilute washed RBCs. Microvesicles were then incubated at varying concentrations with RBCs before flow cytometry and fluorescence microscopy.

Figure 6A, left panel shows the stained MVs. The wash buffer did not contain appreciable lipid dye (Figure 6A, middle panel). When stained MVs and unstained RBCs were combined, there was a population of DiI-positive RBCs that correlated to the number of DiI-positive MVs (Figure 6A, right panel); this was unrelated to the RBC concentration or cytometer flow core width, suggesting that rather than mere co-incidence on the flow cytometer, the MVs were adhering to RBCs.

Figure $6 \mathrm{C}$ is a brightfield image at $100 \times g$ of a single RBC with no apparent distinguishing features. However, the DiI-fluorescence channel (Figure 6D) showed a distinct spot that can be appreciated in the overlaid image (Figure 6E).

These results suggest that MVs may adhere to RBCs, and thus co-sediment with cells. This, in part, may explain the difference seen between RBC-poor supernatant and direct MV enumeration in uncentrifuged blood. This also highlights how even bypassing centrifugation completely by directly diluting blood and then quantifying MVs still will result in underestimates of the true concentration of vesicles within the cellular-rich biological fluid. 

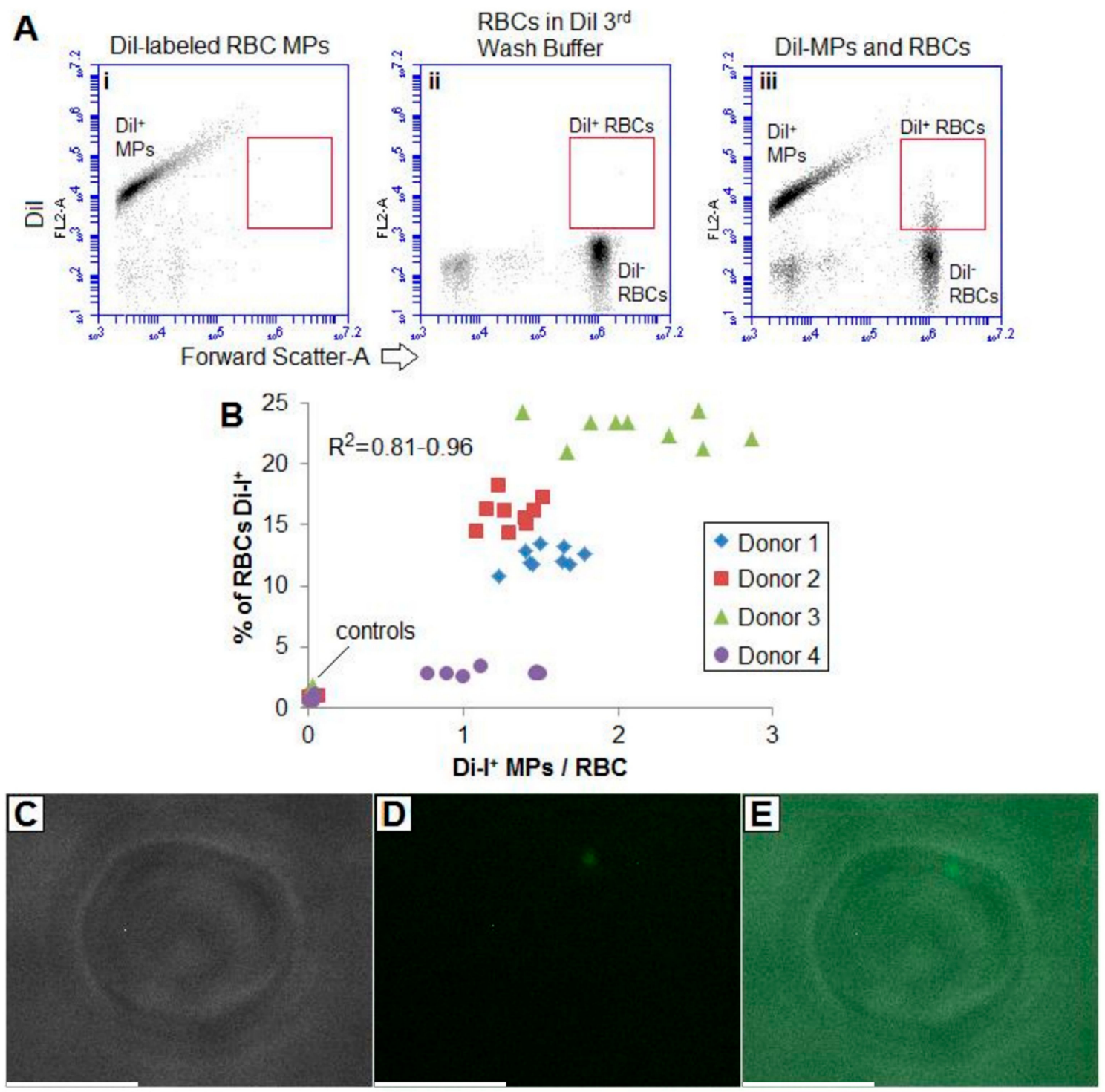

Figure 6. Fluorescent lipid-labeled MPs/MVs adhered to RBCs. (A) To further investigate the discrepancy between RMV concentrations found in direct dilutions of blood compared to RBC-poor supernatant isolated by sedimenting cells overnight, isolated MVs were labeled with DiI and washed 3x (i). The 3rd wash buffer (with any unbound dye) was used to resuspend washed RBCs (ii). When the DiI-MVs were incubated with unlabeled washed cells, there appeared to be DiI-positive RBCs (iii). (B) Normalized to the total cells, there was a DiI-MV concentration-dependent increase in DiI-positive cells. (C) Light micrograph of an RBC, with corresponding (D) DiI-fluorescence and (E) overlay show apparent MV adhered to an otherwise normal-appearing RBC. Bar $=5 \mu \mathrm{m}$.

\subsection{RBC-Derived Macroparticles Are Also Present in Murine Hemolytic Blood}

To examine if the populations of erythrocyte macroparticles and intermediate vesicles were limited to stored blood, blood from 2 different murine models of hemolytic anemia were examined. Uncentrifuged blood from healthy mice and two different models of hemolytic anemia was examined for RBC vesicles using TER119, an antibody against murine glycophorin A, an erythrocyte lineage marker [47].

To ensure that the RBC vesicles were not actually RBC MVs adhered to or overlapping with platelets or platelet- or endothelial-derived MVs, PECAM-1 staining was employed to exclude such events (Figure 7A). Beads, $3 \mu \mathrm{m}$, were again used to qualitatively compare the sizes of cells and vesicles (Figure 7B). 

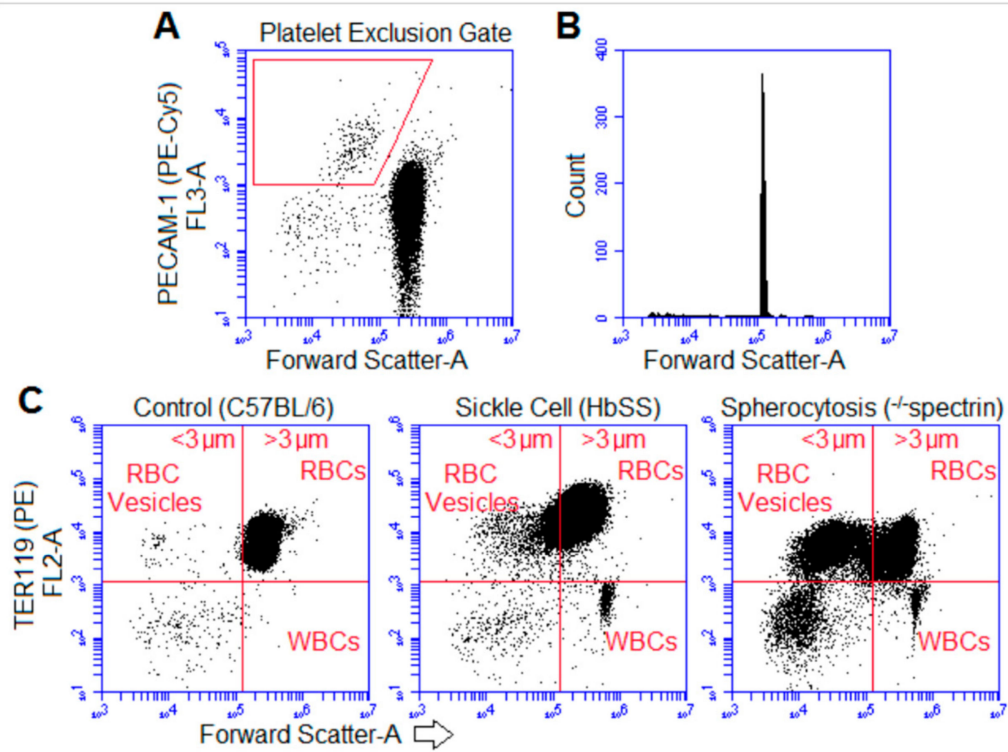

PECAM-1- TER119+ Gated
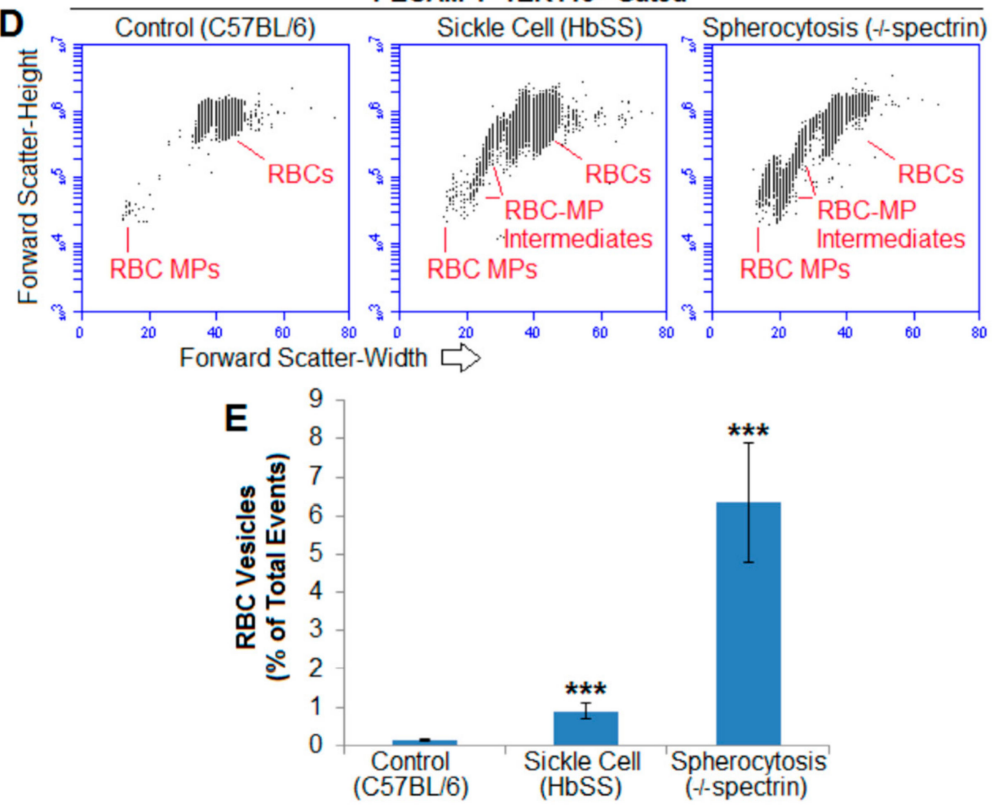

Figure 7. Blood from mouse models of hemolytic anemia contained large and heterogeneously sized vesicles: (A) PECAM-1+ platelets and other MPs/MVs were excluded (red trapezoid exclusion gate) and (B) $3 \mu \mathrm{m}$ beads were used to distinguish vesicles from cells (as murine RBCs are smaller than human). (C) Representative (PECAM-1 platelet/MV excluded) whole blood diluted 1:1000 in normal saline with 10\% BSA and stained for TER119 in healthy control mice (C57BL/6), mice expressing solely human sickle hemoglobin (HbSS), and mice with deficient spectrin modeling hereditary spherocytosis. (D) Representative forward scatter height by width demonstrates heterogeneously sized RBC-MV intermediates in both sickle cell and spherocytosis mouse blood. (E) RBC vesicles smaller than $3 \mu \mathrm{m}$ made up nearly $1 \%$ of all events in the sickle cell mouse blood and over $6 \%$ of all events in spherocytosis mouse blood; ${ }^{* * *} p<0.001$ compared to normal mice; $n=3-5$.

The blood of both hemolytic mice groups showed subcellular RBC particles larger than $1 \mu \mathrm{m}$. Figure 7C,D is representative flow cytometry data of the (PECAM-1 excluded) blood of 3-5 mice per genotype. (The FSC-A of $3 \mu \mathrm{m}$ beads is given for a size reference, and the fluorescence was based on isotype fluorescent controls). Less than $1 \%$ of total cytometry events from the healthy mice were TER119-positive and smaller than $3 \mu \mathrm{m}$ (Figure 7E). However, significantly more heterogeneously sized RBC vesicles were found 
in the uncentrifuged blood of murine models of sickle cell disease and severe hereditary spherocytosis. These erythrocyte-derived particles had a wide size range based on their FSC (thus, size was not readily quantifiable).

\section{Discussion}

The majority of studies describing circulating MPs/MVs use centrifugation to remove cells and platelets before enumerating MPs/MVs. The results presented here directly challenge such practice. We showed that RBC-derived vesicles are not limited to less than 1 micrometer in diameter (a standard that is used for distinguishing platelets from plateletderived MV) and suggest a spectrum of RBC-degradation product sizes. In addition, in congruence with one report directly enumerating RMVs in uncentrifuged blood [9], we showed that the concentration of RMVs decreases exponentially as centrifugation speed increases. Thus, when interpreting data comparing circulating MV concentrations in various diseases, the method to isolate and measure the MVs must be considered.

The principles of particle centrifugation can be described by the Stokes equation, in Equation (1):

$$
v=d^{2} *(p-L) * g / 18 n
$$

where $v$ is the sedimentation rate (velocity) of a spherical particle; $d$, the diameter; $p$ is the particle, and $L$ the medium densities; $\mathrm{n}$ is the viscosity of the medium, and, lastly, $g$ is the gravitational force (RCF). Thus, for a given platelet MV compared to an identically sized RBC MV (assuming MV densities are the same as their respective parent cells, with RBCs nearly $1.1 \mathrm{~g} / \mathrm{mL}(1.0996 \mathrm{~g} / \mathrm{mL})$ [48] and platelets only $1.069 \mathrm{~g} / \mathrm{mL}$ [49]), RBC MV will sediment with a velocity $144 \%$ of that of the platelet MV.

Platelet-derived vesicles or MVs are reportedly the most abundant circulating MVs in the body, and as such, guidelines defining what an MV are largely aimed at excluding MVs from small platelets. Thus, platelet-derived MVs have been suggested as not being larger than $1 \mu \mathrm{m}$ in diameter (particularly, between 0.5 and $0.9 \mu \mathrm{m}$ ) [50]. However, the data presented here represent a novel concept for what constitutes an erythrocyte-derived $\mathrm{MP} / \mathrm{MV}$, as well as their relative abundance. Typical small $(<1 \mu \mathrm{m})$ platelet or cell-derived MVs are generated in response to activation or stimuli, including calcium- or ionophoretreated RBCs as a classic example. However, during hemolysis, there is uncontrolled destruction of erythrocytes, resulting in heterogeneously sized membrane-enveloped cell fragments (vesicles) as shown in this study. Previously MPs/MVs were considered inert cellular debris, but we now have widely available tools to examine these small and transient biological effectors. In like fashion, large RBC fragments have often been referred to as large "debris"; this paper challenges this distinction, suggesting that large debris and microparticles/microvesicles are differently sized vesicles on the same spectrum, resulting from damage and destruction of RBCs; and that the size upper limit of platelet MVs does not apply to RBC MVs.

The platelet MV size guideline has also been derived largely from studies of platelet MVs isolated from platelet-free plasma; however, this article demonstrates centrifugation preferentially removes large (RBC) vesicles. The sedimentation of any given particle depends on the centrifuge as well as properties of the particle and its solution [45]. Blood and plasma samples require an anticoagulant, and so when centrifuging biological fluids, the amount of liquid anticoagulant/saline needs to be considered. Otherwise, centrifugation of samples diluted in anticoagulant, additive solution, or saline (which are nearly half as viscous as plasma, primarily due to the lack of protein) will sediment vesicles faster than those with less anticoagulant. Thus, in order to study MVs in biological fluids and compare across institutions, further refinement of centrifugation as a means to isolate MVs is merited. Data presented here suggest centrifugation-free direct dilution/examination of the biological fluids should also be considered as a means to study MVs preferentially over centrifugation.

The population of cell-to-MV intermediate vesicles or "macroparticles" identified in this work is unlike other RBC vesicles identified before due to a number of reasons. Rather 
than use excessive heat, calcium, calcium ionophore or other artificial vesiculation agents, as has been reported elsewhere, we elected to focus on vesicles formed during hemolysis in more clinically or physiologically relevant scenarios. While RMVs derived in stored blood units may not be physiologic, they are still clinically relevant given such are transfused along with RBCs.

There are differences between RBC-bound hemoglobin and cell-free hemoglobin in their dynamics of gas exchange [21]. The biggest difference is the diffusion-limiting membrane, which causes intra-erythrocytic $\mathrm{mM}$ hemoglobin not to scavenge nitric oxide despite the favorable scavenging kinetics [51]. Additionally, principles of hydrodynamics result in a flow velocity-dependent RBC-free zone [52]. Thus, the physiologic half-life of endothelial produced NO is $1 \mathrm{~ms}$ rather than $1 \mu \mathrm{s}$ as the case would be for (pathologic) cell-free hemoglobin. This is not necessarily the case for MV-containing $\mathrm{Hb}$, as the RBCfree zone is penetrable by smaller vesicles that have been shown to be capable of gas exchange, namely, in scavenging nitric oxide [21]. Thus, there is likely no minimum size an RBC (or vesicular fragment thereof) can be to carry out the primary function of hemoglobin-mediated gas exchange. The size of a hemoglobin-containing vesicle, however, determines how close it will approach the vascular wall and whether or not it will scavenge endothelial-derived NO on the one hand or participate in tissue oxygenation on the other.

What is the minimum size a membrane bilayer-encapsulated hemoglobin-containing vesicle becomes an erythrocytic vesicle instead of an erythrocyte? Clinical diagnostic guidelines suggest that RBCs are microcytic if under 6-6.4 $\mu \mathrm{m}$ maximum in diameter, but the authors are unaware of a minimum size distinguishing a severely microcytic RBC from merely an RBC fragment as they transition along the size spectrum. A relevant article examining the ferric chloride-induced thrombosis model showed that RBC "fragments" with considerable heterogeneity in size played a substantial role in adhesion and thrombosis [30]. Thus, whether through scavenging of NO, seeding adhesion sites for thrombosis, or providing a phospholipid surface required for coagulation, RBC-derived vesicles are important pathological debris in hemolysis.

\section{Materials and Methods}

While flow cytometers were intended to count cells and not subcellular "debris" as vesicles have been called, flow cytometry is used extensively to evaluate microvesicles $[34,43,44,50]$. But as demonstrated previously, not all flow cytometer events are truly vesicles [36], so the findings on over two dozen expired units of RBC macroparticles in humans were confirmed with microscopy as detailed below and also demonstrated in mice models of human diseases. Lastly, as proof-of-principle, we showed that artificial RMVs sediment faster than platelet MVs and that fluorescent lipid-labeled RMVs can stick to RBCs as two ways to show how centrifugation can influence RMV enumeration.

\section{1. $R B C$ and $R M V$ Isolation}

Human blood: Outdated donor units are a known source of human RMVs [11,35]. While these may not be identical to physiologic RMVs, they are clinically relevant as they are transfused along with donor RBCs except in the rare instance a patient is transfusion dependent and needs washed cells [35]. Newly outdated leukocyte-reduced donor units (43-46 days after draw) were from the BloodCenter of Wisconsin (Milwaukee, WI, USA). Fresh blood was drawn (per Children's Hospital of Wisconsin Institution Review Board protocol \#CHW 91/34 GCRC 509, approved on 4/2/2014) from a healthy, consenting adult 9:1 into Acid Citrate Dextrose (ACD) and centrifuged at $500 \times g$ for $15 \mathrm{~min}$ at $22^{\circ} \mathrm{C}$ to isolate RBCs and platelet-rich plasma. In some experiments, RBCs and platelet-rich plasma were subjected to extrusion through $0.45 \mu \mathrm{m}$ pore size membranes to generate similarly sized MVs and, subsequently, centrifuged at different speeds before flow cytometry enumeration. Dilution of donor RBCs was into M199/0.2\% BSA media with 0.1\% EDTA in order to avoid glucose deprivation and subsequent hemolysis [53] or clotting. 
Overnight sedimentation was performed by gently mixing and then sterilely withdrawing $10 \mathrm{~mL}$ of blood from the outdated unit bag through a $16 \times \mathrm{g}$ needle to avoid any mechanical lysis, and then slowly transferring that $10 \mathrm{~mL}$ to centrifuge tubes that were then allowed to sit upright overnight for 12-16 $\mathrm{h}$. To prevent any change in temperature, all this was done in a $4{ }^{\circ} \mathrm{C}$ room.

Mice: Characteristics of MVs in healthy human volunteers have been shown to vary by gender and menstrual cycle [54], diet [55,56], smoking status [56], and race [57]. To bypass such heterogeneities, well-characterized mouse models of human hemolytic anemia were examined. Berkeley Sickle Cell Disease (SCD) mice have a phenotype with features of severe human SCD $[58,59]$. The WBB6F1-sph/sph mice have severe hereditary spherocytosis due to the fact of a deletion in the erythroid $\alpha$-spectrin gene [60]. Mice protocols were approved by the Institutional Animal Care and Use Committee of the Medical College of Wisconsin, protocol \#AUA00000142 approved on 30 January 2014. Blood was collected from anesthetized mice by cardiac puncture using 20 gauge needles and drawn 5:1 into ACD and diluted 1:1000 in sterile-filtered normal saline with 10\% BSA. (This saline is slightly hypotonic for murine blood but was used to avoid further dehydration and possible subsequent spiculation/vesiculation [53].)

\subsection{Cell and MV Staining}

Incubations were done on ice at $4{ }^{\circ} \mathrm{C}$ in the dark for $>15$ min unless otherwise stated. Anti-human glycophorin A and anti-murine TER119 antibodies were from eBioscience (San Diego, CA, USA) and added to cell suspensions at 1:500-1:1000. Glycophorin A, also known as CD235a, is uniquely exposed on the surface of red blood cells and is associated with the RBC lipid bilayer [61,62]. This protein is widely accepted by hematologists as a marker specific for RBC membranes and was chosen as a way to confirm the origin of measured particulate was from RBCs. TER119 is a molecule associated with murine glycophorin A, and is used similarly as a marker of RBCs [47]. Anti-PECAM-1 antibodies (from Becton Dickinson, Franklin Lakes, NJ, USA) was used as a marker of platelet or endothelial origin, and staining was performed with anti-PECAM- 1 antibodies as reported previously $[11,36]$ to excluded such events for subsequent flow cytometry experiments.

Lactadherin-FITC (Haematologic Technologies Inc., Essex Junction, VT, USA) was used as a calcium-independent PS-probe as per the manufacturer's instruction (using 1:100 final dilution). Fluorescent lipid-labeling of MVs was done by incubating MV-rich supernatant (isolated by centrifugation at $1500 \times g$ for $15 \mathrm{~min}$ at $4{ }^{\circ} \mathrm{C}$ ) with $20 \mu \mathrm{g} / \mathrm{mL}$ DiI (a highly-lipophilic membrane dye) at $37^{\circ} \mathrm{C}$ for $20-30 \mathrm{~min}$. The MVs were then isolated by centrifugation at $15,000 \times g$ for $15-30$ min and washed with M199/2\% BSA with $0.1 \%$ EDTA. The RBCs were resuspended in the third wash buffer to control for residual dye. The DiI-MVs were incubated with cells for $15 \mathrm{~min}$ at $37^{\circ} \mathrm{C}$.

\subsection{Flow Cytometry}

Flow cytometry was performed on an Accuri C6 (BDIS, San Jose, CA, USA) as described previously [10,41]. The Accuri C6 forward scatter height (FSC-H) threshold was 10,000 as this provided an acceptable minimum background of less than 100 events per minute on sterile-filtered saline. Beads with various diameters were used to estimate vesicle size and confirm the cytometer reported concentrations as described elsewhere [10,22]. Samples were gently mixed immediately prior to flow cytometry. Analysis of data was conducted using the C-Flow Plus (BDIS). The linear range of the cytometer was established by diluting 3-4 samples in saline and comparing the event rate; the linear range was determined by minimizing the variance from a linear fit of the data through $3-5$ points.

\subsection{Fluorescence Microscopy}

Fluorescently labeled cells and RMVs were plated and immediately imaged on a Nikon TE200 (Melville, NY, USA) using 100× magnification. Images acquisition was via Photometrics CoolSNAP-ES camera (Tucson, AZ, USA) using Metamorph (Molecular 
Devices, Sunnyvale, CA, USA). Image brightness and contrast were adjusted using ImageJ (US NIH, http:/ / imagej.nih.gov/ij/).

\subsection{Statistical Analysis}

Statistical analysis was conducted using the Student's 2-tailed $t$-test without assuming equal variance. One-way ANOVA was used to compare multiple manipulations. For data that varied by an order of magnitude, data were first log-transformed prior to applying the $t$-test. An alpha of 0.05 determined significance. Data are presented as the mean \pm standard error of the mean.

Author Contributions: Conceptualization, methodology, software, validation, formal analysis and investigation, M.C.L. and N.H.; resources, C.A.H.; data curation, M.C.L.; writing-original draft preparation, M.C.L.; writing-review and editing, C.A.H. and N.H.; visualization, M.C.L.; supervision, C.A.H. and N.H.; project administration, C.A.H. and N.H.; funding acquisition, C.A.H. All authors have read and agreed to the published version of the manuscript.

Funding: M.C.L. was a member of the MCW-MSTP which was partially supported by a T32 grant from NIGMS, GM080202. M.C.L. and C.A.H. were supported by the Midwest Athletes Against Childhood Cancer Fund.

Institutional Review Board Statement: The study was conducted on human subjects/biological material according to the guidelines of the Declaration of Helsinki, and approved by the Institutional Review Board of Children's Hospital of Wisconsin Institution Review Board protocol \#CHW 91/34 GCRC 509, approved on 4/2/2014; and mice protocols were approved by the Institutional Animal Care and Use Committee of the Medical College of Wisconsin, protocol \#AUA00000142 on 1/30/2014.

Informed Consent Statement: Informed consent was obtained from all subjects involved in the study.

Data Availability Statement: Data are available upon reasonable request to the corresponding author.

Acknowledgments: We acknowledge the invaluable help of Nic Ratto in his technical support with the centrifugation and microscopy and Nancy Wandersee in her proofing of the manuscript.

Conflicts of Interest: The authors declare no relevant conflict of interest.

$\begin{array}{ll}\text { Abbreviations } \\ \text { FSC } & \text { Forward Scatter } \\ \text { MP/MV } & \text { Microparticles or microvesicles } \\ \text { PECAM-1 } & \text { Platelet Endothelial Cell Adhesion Molecule-1 } \\ \text { PMV } & \text { Platelet-derived microvesicles } \\ \text { RMV } & \text { Red blood cell-derived microvesicles } \\ \text { SSC } & \text { Side Scatter } \\ \text { PS } & \text { Phosphatidylserine } \\ \text { SCD } & \text { Sickle Cell Disease }\end{array}$

\section{References}

1. Dignat-George, F.; Boulanger, C.M. The Many Faces of Endothelial Microparticles. Arterioscler. Thromb. Vasc. Biol. 2011, 31, 27-33. [CrossRef] [PubMed]

2. Rak, J. Microparticles in Cancer. Semin. Thromb. Hemost. 2010, 36, 888-906. [CrossRef]

3. Wang, B.; Li, T.; Han, X.; Li, Y.; Cheng, W.; Wang, L.; Lu, Z.; Yang, J.; Zhao, M. The Level of Circulating Microparticles in Patients with Coronary Heart Disease: A Systematic Review and Meta-Analysis. J Cardiovasc. Transl. Res. 2020, 13, 702-712. [CrossRef]

4. Willekens, F.L.A.; Werre, J.M.; Groenen-Döpp, Y.A.M.; Roerdinkholder-Stoelwinder, B.; Pauw, B.D.; Bosman, G.J.C.G.M. Erythrocyte Vesiculation: A Self-Protective Mechanism? Br. J. Haematol. 2008, 141, 549-556. [CrossRef] [PubMed]

5. Zucker-Franklin, D.; Karpatkin, S. Red-Cell and Platelet Fragmentation in Idiopathic Autoimmune Thrombocytopenic Purpura. N. Engl. J. Med. 1977, 297, 517-523. [CrossRef]

6. Larson, M.C.; Hillery, C.A.; Hogg, N. Circulating Membrane-Derived Microvesicles in Redox Biology. Free Radic. Biol. Med. 2014, 73, 214-228. [CrossRef] [PubMed] 
7. Kriebardis, A.G.; Antonelou, M.H.; Stamoulis, K.E.; Economou-Petersen, E.; Margaritis, L.H.; Papassideri, I.S. RBC-Derived Vesicles during Storage: Ultrastructure, Protein Composition, Oxidation, and Signaling Components. Transfusion (Paris) 2008, 48, 1943-1953. [CrossRef] [PubMed]

8. Nantakomol, D.; Palasuwan, A.; Chaowanathikhom, M.; Soogarun, S.; Imwong, M. Red Cell and Platelet-Derived Microparticles Are Increased in G6PD-Deficient Subjects. Eur. J. Haematol. 2012, 89, 423-429. [CrossRef]

9. Rubin, O.; Crettaz, D.; Canellini, G.; Tissot, J.-D.; Lion, N. Microparticles in Stored Red Blood Cells: An Approach Using Flow Cytometry and Proteomic Tools. Vox Sang. 2008, 95, 288-297. [CrossRef] [PubMed]

10. Tissot, J.-D.; Rubin, O.; Canellini, G. Analysis and Clinical Relevance of Microparticles from Red Blood Cells. Curr. Opin. Hematol. 2010, 17, 571-577. [CrossRef] [PubMed]

11. Larson, M.C.; Woodliff, J.E.; Hillery, C.A.; Kearl, T.J.; Zhao, M. Phosphatidylethanolamine Is Externalized at the Surface of Microparticles. Biochim. Biophys. Acta 2012, 1821, 1501-1507. [CrossRef] [PubMed]

12. Tavoosi, N.; Davis-Harrison, R.L.; Pogorelov, T.V.; Ohkubo, Y.Z.; Arcario, M.J.; Clay, M.C.; Rienstra, C.M.; Tajkhorshid, E.; Morrissey, J.H. Molecular Determinants of Phospholipid Synergy in Blood Clotting. J. Biol. Chem. 2011, 286, 23247-23253. [CrossRef] [PubMed]

13. Fadok, V.A.; Bratton, D.L.; Rose, D.M.; Pearson, A.; Ezekewitz, R.A.; Henson, P.M. A Receptor for Phosphatidylserine-Specific Clearance of Apoptotic Cells. Nature 2000, 405, 85-90. [CrossRef] [PubMed]

14. Willekens, F.L.A.; Werre, J.M.; Kruijt, J.K.; Roerdinkholder-Stoelwinder, B.; Groenen-Döpp, Y.A.M.; van den Bos, A.G.; Bosman, G.J.C.G.M.; van Berkel, T.J.C. Liver Kupffer Cells Rapidly Remove Red Blood Cell-Derived Vesicles from the Circulation by Scavenger Receptors. Blood 2005, 105, 2141-2145. [CrossRef] [PubMed]

15. Simhadri, V.R.; Andersen, J.F.; Calvo, E.; Choi, S.-C.; Coligan, J.E.; Borrego, F. Human CD300a Binds to Phosphatidylethanolamine and Phosphatidylserine, and Modulates the Phagocytosis of Dead Cells. Blood 2012, 119, 2799-2809. [CrossRef]

16. Frey, B.; Gaipl, U.S. The Immune Functions of Phosphatidylserine in Membranes of Dying Cells and Microvesicles. Semin. Immunopathol. 2011, 33, 497-516. [CrossRef]

17. Sadallah, S.; Eken, C.; Schifferli, J.A. Ectosomes as Immunomodulators. Semin. Immunopathol. 2010, 33, 487-495. [CrossRef]

18. Zecher, D.; Cumpelik, A.; Schifferli, J.A. Erythrocyte-Derived Microvesicles Amplify Systemic Inflammation by ThrombinDependent Activation of Complement. Arterioscler. Thromb. Vasc. Biol. 2014, 34, 313-320. [CrossRef]

19. Noubouossie, D.F.; Henderson, M.W.; Mooberry, M.; Ilich, A.; Ellsworth, P.; Piegore, M.; Skinner, S.C.; Pawlinski, R.; Welsby, I.; Renné, T.; et al. Red Blood Cell Microvesicles Activate the Contact System, Leading to Factor IX Activation via 2 Independent Pathways. Blood 2020, 135, 755-765. [CrossRef]

20. Shet, A.S.; Aras, O.; Gupta, K.; Hass, M.J.; Rausch, D.J.; Saba, N.; Koopmeiners, L.; Key, N.S.; Hebbel, R.P. Sickle Blood Contains Tissue Factor-Positive Microparticles Derived from Endothelial Cells and Monocytes. Blood 2003, 102, 2678-2683. [CrossRef]

21. Donadee, C.; Raat, N.J.H.; Kanias, T.; Tejero, J.; Lee, J.S.; Kelley, E.E.; Zhao, X.; Liu, C.; Reynolds, H.; Azarov, I.; et al. Nitric Oxide Scavenging by Red Blood Cell Microparticles and Cell-Free Hemoglobin as a Mechanism for the Red Cell Storage Lesion. Circulation 2011, 124, 465-476. [CrossRef] [PubMed]

22. Vlaar, A.P.J.; Hofstra, J.J.; Levi, M.; Kulik, W.; Nieuwland, R.; Tool, A.T.J.; Schultz, M.J.; de Korte, D.; Juffermans, N.P. Supernatant of Aged Erythrocytes Causes Lung Inflammation and Coagulopathy in a "Two-Hit" in Vivo Syngeneic Transfusion Model. Anesthesiology 2010, 113, 92-103. [CrossRef] [PubMed]

23. Jy, W.; Ricci, M.; Shariatmadar, S.; Gomez-Marin, O.; Horstman, L.H.; Ahn, Y.S. Microparticles in Stored Red Blood Cells as Potential Mediators of Transfusion Complications. Transfusion (Paris) 2011, 51, 886-893. [CrossRef] [PubMed]

24. Pinheiro, M.K.; Tamagne, M.; Elayeb, R.; Andrieu, M.; Pirenne, F.; Vingert, B. Blood Microparticles Are a Component of Immune Modulation in Red Blood Cell Transfusion. Eur. J. Immunol. 2020, 50, 1237-1240. [CrossRef] [PubMed]

25. Van Beers, E.J.; Schaap, M.C.L.; Berckmans, R.J.; Nieuwland, R.; Sturk, A.; van Doormaal, F.F.; Meijers, J.C.M.; Biemond, B.J. CURAMA study group Circulating Erythrocyte-Derived Microparticles Are Associated with Coagulation Activation in Sickle Cell Disease. Haematologica 2009, 94, 1513-1519. [CrossRef]

26. Camus, S.M.; Gausserès, B.; Bonnin, P.; Loufrani, L.; Grimaud, L.; Charue, D.; De Moraes, J.A.; Renard, J.-M.; Tedgui, A.; Boulanger, C.M.; et al. Erythrocyte Microparticles Can Induce Kidney Vaso-Occlusions in a Murine Model of Sickle Cell Disease. Blood 2012, 120, 5050-5058. [CrossRef]

27. Mullier, F.; Bailly, N.; Chatelain, C.; Chatelain, B.; Dogné, J.-M. Pre-Analytical Issues in the Measurement of Circulating Microparticles: Current Recommendations and Pending Questions. J. Thromb. Haemost. 2013, 11, 693-696. [CrossRef]

28. Cointe, S.; Judicone, C.; Robert, S.; Mooberry, M.J.; Poncelet, P.; Wauben, M.; Nieuwland, R.; Key, N.S.; Dignat-George, F.; Lacroix, R. Standardization of Microparticle Enumeration across Different Flow Cytometry Platforms: Results of a Multicenter Collaborative Workshop. J. Thromb. Haemost. 2017, 15, 187-193. [CrossRef]

29. Poncelet, P.; Robert, S.; Bouriche, T.; Bez, J.; Lacroix, R.; Dignat-George, F. Standardized Counting of Circulating Platelet Microparticles Using Currently Available Flow Cytometers and Scatter-Based Triggering: Forward or Side Scatter? Cytom. Part J. Int. Soc. Anal. Cytol. 2016, 89, 148-158. [CrossRef]

30. Barr, J.D.; Chauhan, A.K.; Schaeffer, G.V.; Hansen, J.K.; Motto, D.G. Red Blood Cells Mediate the Onset of Thrombosis in the Ferric Chloride Murine Model. Blood 2013, 121, 3733-3741. [CrossRef]

31. Shet, A.S. Characterizing Blood Microparticles: Technical Aspects and Challenges. Vasc. Health Risk Manag. 2008, 4, 769-774. [CrossRef] 
32. Dey-Hazra, E.; Hertel, B.; Kirsch, T.; Woywodt, A.; Lovric, S.; Haller, H.; Haubitz, M.; Erdbruegger, U. Detection of Circulating Microparticles by Flow Cytometry: Influence of Centrifugation, Filtration of Buffer, and Freezing. Vasc. Health Risk Manag. 2010, 6, 1125-1133. [CrossRef] [PubMed]

33. Yuana, Y.; Bertina, R.M.; Osanto, S. Pre-Analytical and Analytical Issues in the Analysis of Blood Microparticles. Thromb. Haemost. 2011, 105, 396-408. [CrossRef] [PubMed]

34. Van Ierssel, S.H.; Van Craenenbroeck, E.M.; Conraads, V.M.; Van Tendeloo, V.F.; Vrints, C.J.; Jorens, P.G.; Hoymans, V.Y. Flow Cytometric Detection of Endothelial Microparticles (EMP): Effects of Centrifugation and Storage Alter with the Phenotype Studied. Thromb. Res. 2010, 125, 332-339. [CrossRef] [PubMed]

35. Larson, M.C.; Karafin, M.S.; Hillery, C.A.; Hogg, N. Phosphatidylethanolamine Is Progressively Exposed in RBCs during Storage. Transfus. Med. 2017, 27, 136-141. [CrossRef]

36. Larson, M.C.; Luthi, M.R.; Hogg, N.; Hillery, C.A. Calcium-Phosphate Microprecipitates Mimic Microparticles When Examined with Flow Cytometry. Cytom. Part J. Int. Soc. Anal. Cytol. 2013, 83, 242-250. [CrossRef]

37. Pankoui Mfonkeu, J.B.; Gouado, I.; Fotso Kuaté, H.; Zambou, O.; Amvam Zollo, P.H.; Grau, G.E.R.; Combes, V. Elevated Cell-Specific Microparticles Are a Biological Marker for Cerebral Dysfunctions in Human Severe Malaria. PLoS ONE 2010, 5 , e13415. [CrossRef]

38. Mrvar-Brecko, A.; Sustar, V.; Jansa, V.; Stukelj, R.; Jansa, R.; Mujagić, E.; Kruljc, P.; Iglic, A.; Hägerstrand, H.; Kralj-Iglic, V. Isolated Microvesicles from Peripheral Blood and Body Fluids as Observed by Scanning Electron Microscope. Blood Cells Mol. Dis. 2010, 44, 307-312. [CrossRef]

39. Lelkes, G.; Fodor, I. Formation of Large, Membrane Skeleton-Free Erythrocyte Vesicles as a Function of the Intracellular PH and Temperature. Biochim. Biophys. Acta 1991, 1065, 135-144. [CrossRef]

40. Leonards, K.S.; Ohki, S. Isolation and Characterization of Large (0.5-1.0 Micron) Cytoskeleton-Free Vesicles from Human and Rabbit Erythrocytes. Biochim. Biophys. Acta 1983, 728, 383-393. [CrossRef]

41. Allan, D.; Thomas, P.; Limbrick, A.R. The Isolation and Characterization of $60 \mathrm{Nm}$ Vesicles ('nanovesicles') Produced during Ionophore A23187-Induced Budding of Human Erythrocytes. Biochem. J. 1980, 188, 881-887. [CrossRef] [PubMed]

42. Allan, D.; Billah, M.M.; Finean, J.B.; Michell, R.H. Release of Diacylglycerol-Enriched Vesicles from Erythrocytes with Increased Intracellular $\left(\mathrm{Ca}^{2+}\right)$. Nature 1976, 261, 58-60. [CrossRef]

43. Mullier, F.; Bailly, N.; Chatelain, C.; Dogné, J.M.; Chatelain, B. More on: Calibration for the Measurement of Microparticles: Needs, Interests, and Limitations of Calibrated Polystyrene Beads for Flow Cytometry-Based Quantification of Biological Microparticles. J. Thromb. Haemost. 2011, 9, 1679-1681; author reply 1681-1682. [CrossRef] [PubMed]

44. Van der Pol, E.; van Gemert, M.J.C.; Sturk, A.; Nieuwland, R.; van Leeuwen, T.G. Single vs. Swarm Detection of Microparticles and Exosomes by Flow Cytometry. J. Thromb. Haemost. 2012, 10, 919-930. [CrossRef] [PubMed]

45. Momen-Heravi, F.; Balaj, L.; Alian, S.; Trachtenberg, A.J.; Hochberg, F.H.; Skog, J.; Kuo, W.P. Impact of Biofluid Viscosity on Size and Sedimentation Efficiency of the Isolated Microvesicles. Front. Physiol. 2012, 3, 162. [CrossRef] [PubMed]

46. Lacroix, R.; Robert, S.; Poncelet, P.; Dignat-George, F. Overcoming Limitations of Microparticle Measurement by Flow Cytometry. Semin. Thromb. Hemost. 2010, 36, 807-818. [CrossRef]

47. Kina, T.; Ikuta, K.; Takayama, E.; Wada, K.; Majumdar, A.S.; Weissman, I.L.; Katsura, Y. The Monoclonal Antibody TER-119 Recognizes a Molecule Associated with Glycophorin A and Specifically Marks the Late Stages of Murine Erythroid Lineage. Br. J. Haematol. 2000, 109, 280-287. [CrossRef]

48. Ponder, E. The Relation Between Red Blood Cell Density and Corpuscular Hemoglobin Concentration. J. Biol. Chem. 1942, 144, 333-338. [CrossRef]

49. Corash, L.; Tan, H.; Gralnick, H.R. Heterogeneity of Human Whole Blood Platelet Subpopulations. I. Relationship between Buoyant Density, Cell Volume, and Ultrastructure. Blood 1977, 49, 71-87. [CrossRef]

50. Lacroix, R.; Robert, S.; Poncelet, P.; Kasthuri, R.S.; Key, N.S.; Dignat-George, F. ISTH SSC Workshop Standardization of PlateletDerived Microparticle Enumeration by Flow Cytometry with Calibrated Beads: Results of the International Society on Thrombosis and Haemostasis SSC Collaborative Workshop. J. Thromb. Haemost. 2010, 8, 2571-2574. [CrossRef] [PubMed]

51. Azarov, I.; Liu, C.; Reynolds, H.; Tsekouras, Z.; Lee, J.S.; Gladwin, M.T.; Kim-Shapiro, D.B. Mechanisms of Slower Nitric Oxide Uptake by Red Blood Cells and Other Hemoglobin-Containing Vesicles. J. Biol. Chem. 2011, 286, 33567-33579. [CrossRef] [PubMed]

52. Liao, J.C.; Hein, T.W.; Vaughn, M.W.; Huang, K.T.; Kuo, L. Intravascular Flow Decreases Erythrocyte Consumption of Nitric Oxide. Proc. Natl. Acad. Sci. USA 1999, 96, 8757-8761. [CrossRef] [PubMed]

53. Wandersee, N.J.; Punzalan, R.C.; Rettig, M.P.; Kennedy, M.D.; Pajewski, N.M.; Sabina, R.L.; Paul Scott, J.; Low, P.S.; Hillery, C.A. Erythrocyte Adhesion Is Modified by Alterations in Cellular Tonicity and Volume. Br. J. Haematol. 2005, 131, 366-377. [CrossRef]

54. Toth, B.; Nikolajek, K.; Rank, A.; Nieuwland, R.; Lohse, P.; Pihusch, V.; Friese, K.; Thaler, C.J. Gender-Specific and Menstrual Cycle Dependent Differences in Circulating Microparticles. Platelets 2007, 18, 515-521. [CrossRef] [PubMed]

55. Tushuizen, M.E.; Nieuwland, R.; Rustemeijer, C.; Hensgens, B.E.; Sturk, A.; Heine, R.J.; Diamant, M. Elevated Endothelial Microparticles Following Consecutive Meals Are Associated with Vascular Endothelial Dysfunction in Type 2 Diabetes. Diabetes Care 2007, 30, 728-730. [CrossRef] 
56. Gordon, C.; Gudi, K.; Krause, A.; Sackrowitz, R.; Harvey, B.-G.; Strulovici-Barel, Y.; Mezey, J.G.; Crystal, R.G. Circulating Endothelial Microparticles as a Measure of Early Lung Destruction in Cigarette Smokers. Am. J. Respir. Crit. Care Med. 2011, 184, 224-232. [CrossRef]

57. Brown, M.D.; Feairheller, D.L.; Thakkar, S.; Veerabhadrappa, P.; Park, J.-Y. Racial Differences in Tumor Necrosis Factor- $\alpha$-Induced Endothelial Microparticles and Interleukin-6 Production. Vasc. Health Risk Manag. 2011, 7, 541-550. [CrossRef]

58. Pászty, C.; Brion, C.M.; Manci, E.; Witkowska, H.E.; Stevens, M.E.; Mohandas, N.; Rubin, E.M. Transgenic Knockout Mice with Exclusively Human Sickle Hemoglobin and Sickle Cell Disease. Science 1997, 278, 876-878. [CrossRef]

59. Frei, A.C.; Guo, Y.; Jones, D.W.; Pritchard, K.A.; Fagan, K.A.; Hogg, N.; Wandersee, N.J. Vascular Dysfunction in a Murine Model of Severe Hemolysis. Blood 2008, 112, 398-405. [CrossRef]

60. Wandersee, N.J.; Birkenmeier, C.S.; Gifford, E.J.; Mohandas, N.; Barker, J.E. Murine Recessive Hereditary Spherocytosis, Sph/Sph, Is Caused by a Mutation in the Erythroid Alpha-Spectrin Gene. Hematol. J. 2000, 1, 235-242. [CrossRef]

61. Grant, C.W.M.; McConnell, H.M. Glycophorin in Lipid Bilayers. Proc. Natl. Acad. Sci. USA 1974, 71, 4653-4657. [CrossRef] [PubMed]

62. Furthmayr, H.; Marchesi, V.T. Subunit Structure of Human Erythrocyte Glycophorin A. Biochemistry 1976, 15, 1137-1144. [CrossRef] [PubMed] 